venous use of the type IV phosphodiesterase inhibitor enoximone. ${ }^{\prime}$ We describe a case of tonic-clonic convulsions associated with intra venous administration of enoximone, a possible adverse effect that has hitherto not been reported

A 66 year old white man was admitted with large anteroseptal myocardial infarction due to occlusion of the left anterior descending coronary artery. He developed a ventricular septal defect within 48 hours of admission. An emergency closure of the defect was carried out with a Dacron patch in combination with double aortocoronary bypass grafting. Before the operation the patien was in severe heart failure, and at operation the infarction was seen to have affected the anterior two thirds of the interventricular septum.

After operation the patient required intra-aortic balloon counterpulsation in addition to infusions of adrenaline $(0 \cdot 04-0 \cdot 1 \mu \mathrm{g} / \mathrm{kg} / \mathrm{min})$, dopamine $(10 \mu \mathrm{g} / \mathrm{kg} / \mathrm{min})$, and amiodarone $(1.2 \mathrm{~g}$ ove $24 \mathrm{hrs}$ ). When enoximone was added to this regimen as a continuous infusion $(6 \mu \mathrm{g} / \mathrm{kg} / \mathrm{min})$ he developed an offensive, watery diarrhoea, a documented complication of treatment, and tonic-clonic convulsions. Both the diarrhoea and convulsions subsided when enoximone was discontinued. The patient also required a period of arteriovenous haemofiltration and haemodialysis in the early postoperative recovery period to combat acute tubular necrosis. Further recovery was satisfactory and he was discharged home 36 days after surgery. Neurological examination, including perimetry, during his hospital stay and after discharge did not show any abnormalities.

Enoximone is a new type IV phosphodiesterase inhibitor, which is an extremely useful inodilator in patients who are critically ill after cardiac surgery. ${ }^{2}$ Other phosphodiesterase inhibitors have been shown to cause profound and potentially dangerous central nervous system stimulation including focal and generalised convulsions, occasionally refractory to anticonvulsant treatment. Could this be true of enoximone too?

Crawford MH. Intravenous use of enoximone. Am 7 Cardiol $1987 ; 60: 42-5 \mathrm{C}$.

Anonymous. Enoximone [Editorial]. Lancet 1988;i: 1085-6.

Gillman AG, Goodman LS, Rall TW, Murad F, eds. Goodma and Gilman's the pharmacological basis of therapeutics. London Baillière Tindall, 1985:590.

\section{Acute dystonia induced by midazolam and abolished by flumazenil}

Drs Iwona H Stolarek and Michael J Ford (Eastern General Hospital, Edinburgh EH6 7LN) write: Dystonic reactions are well recognised following the acute and chronic administration of phenothiazine and butyrophenone neuroleptic agents. Benzodiazepines have also been implicated in the development of tardive dyskinesias despite the fact that they are used to treat such disorders. We describe a patient who developed an acute dystonic reaction after intravenous midazolam which rapidly reversed after administration of the benzodiazepine antagonist flumazenil.

A previously fit 14 year old schoolboy taking no drugs underwent upper intestinal endoscopy in the investigation of dyspepsia. Sedation was achieved with midazolam $5 \mathrm{mg}$ intravenously $(0.1 \mathrm{mg} / \mathrm{kg})$. He became acutely distressed and appeared to be resisting the procedure, which was then stopped. On examination he was conscious but mute and crying abnormally with intense akathisia and lingual dyskinesia. The acute dystonia was rapidly abolished after the administration of flumazenil $250 \mu \mathrm{g}$ intravenously.

Benzodiazepines facilitate the inhibitory effects of both $\gamma$-aminobutryric acid at the presynaptic junction and glycine at the postsynaptic junction. -Aminobutyric acid and glycine are the two major inhibitory neurotransmitters and act as neurotransmitters at $50-75 \%$ of all synapses within the central nervous system. Their effects at receptor sites are competitively antagonised by flumazenil, an imidazobenzodiazepine.

There are no published reports of acute dystonic reactions after intravenous midazolam, though several cases have been reported to the Committee on Safety of Medicines (personal communication). Tardive dyskinesia has, however, been recorded after long term benzodiazepine treatment. "

The occurrence of an acute dystonia induced by midazolam and abolished by flumazenil is strong supportive evidence that benzodiazepines disrup the interplay between dopamine and $\gamma$-aminobutyric acid receptors in the brain stem. Dystonic reactions, and especially akathisia, after intravenous sedation with benzodiazepines may occur more commonly than is recognised and be dismissed as resistance to the procedure. We suggest that practitioners should be more aware of this possibility and, when suspected, administer flumazenil.

1 Kaplan SR, Murkofsky C. Oral-buccal dyskinesia symptom asssociated with low-dose

Snydner SH, Enna SJ, Young, AB. Brain mechanisms associated with therapeutic actions of benzodiazepines: focus on neuroransmitters. Am f Psychiatry 1977:134:662-5.

3 Rosenbaum AH, De La Fuente JR. Benzodiazepines and tardive dyskinesia. Lancet 1979;ii:900.

\section{Hypertensive crisis precipitated by a monoamine oxidase inhibitor in a patient with phaeochromocytoma}

Drs R F Cook (St Bernard's Hospital, Southal UB1 3EU) and D KaTRITSIS (Cardiac Department, St Thomas's Hospital, London SE1 7EH) write: Pharmacological provocation of hypertension in patients with phaeochromocytoma has been described for such psychotropic agents as tricyclic antidepressants. ${ }^{1}$ To our knowledge there has been no such report implicating monoamine oxidase inhibitors. We report a phaeochromocytoma that presented as discrete episodes of headache, anxiety, and hypertension after a single dose of the monoamine oxidase inhibitor tranylcypromine had been given.

A 37 year old white man was admitted to hospital for treatment of neurotic depression. Examination revealed marked agitation, depressed mood, and prominent suicidal thoughts of a recurren obsessional nature. Physical examination was unremarkable apart from a blood pressure of $190 / 100 \mathrm{~mm} \mathrm{Hg}$ in both arms, lying and standing There were no neck or abdominal bruits. Examination of the optic fundi showed grade 1 hypertensive retinopathy. Although his blood pressure had been found to be mildly elevated at several previous medical examinations, the remainder of the medical history was unremarkable. The family history showed hypertension in both parents.

Initial treatment with mianserin $90 \mathrm{mg}$ daily and chlordiazepoxide $25 \mathrm{mg}$ three times a day supplemented by a short course of electroconvulsive therapy (six treatments in all) did not produce a satisfactory response. A monoamine oxidase inhibitor was therefore added to the regimen, and after a single dose of Parstelin (10 $\mathrm{mg}$ tranylcypromine and $1 \mathrm{mg}$ trifluoperazine he had three discrete episodes of acute anxiety, flushing, headache, and hypertension. The highes blood pressure recorded was $220 / 110 \mathrm{~mm} \mathrm{Hg}$. The patient had not consumed any food containing tyramine during his stay in the hospital.

The 24 hour estimation of urinary vanillomandelic acid was 25-35 $\mu \mathrm{mol}$ (reference range up to $35 \mu \mathrm{mol}$ ). Abdominal ultrasound showed an echogenic area $4.5 \mathrm{~cm}$ in diameter in the lef suprarenal region, and minor displacement of the upper pole of the left kidney was seen on intravenous pyelography. A computed tomography scan of the abdomen confirmed the presence of a smooth round suprarenal mass $4 \mathrm{~cm}$ in diameter, which was removed at operation. $\mathrm{Al}$ though cystic in nature, the tumour was seen on histological examination to be typical of phaeochromocytoma of benign type. Postoperatively the patient's blood pressure returned to normal, although his mental state remained largely unchanged.

The actions of sympathomimetic amines are potentiated by monoamine oxidase inhibitors. The effect is greater with indirectly acting amines (tyramine, amphetamine) as catecholamines when given are largely inactivated by catechol- $\mathrm{O}$ methyltransferase and by neuronal uptake. As monoamine oxidase constantly deaminates intracellular norepinephrine in presynaptic adrenergic neurons, however, provocation of hypertension in patients hypersecreting norepinephrine should be expected. Spontaneous hypertensive episodes produced by monoamine oxidase inhibitors have been described, ${ }^{3}$ and it seems possible that, unless hypertension is a rare idiosyncratic reaction to monoamine oxidase inhibitors, these patients had an undiagnosed phaeochromocytoma.

1 Kaplan MN. Pheochromocytoma. In: Braunwald E, ed. Hear disease. Philadelphia: W B Saunders, 1988:847-8.

Baldessarini RJ. Monoamine oxidase inhibitors. In: Gilman AG, Goodman LS, Rall TW, Murad F, eds. Goodman and Gilman's the pharmacological basis of therapeutics. New York: Macmillan. 1985:423-6.

3 Fallon B, Foote B, Walsh BT, Roose SP. "Spontaneous" hypertensive episodes with monoamine oxidase inhibitors. $\mathcal{F}$ Clin Psychiatry 1988;49:163-5.

\section{Clinical signs of amyotrophic lateral sclerosis developing after polyradiculoneuropathy associated with amitriptyline}

Drs Didier Leys and Henri Petit (Department of Neurology, University of Lille, Hôpital B, 59037 Lille, France) write: In 1987 we reported a case of acute polyradiculoneuropathy following an amitriptyline overdose. ${ }^{3}$ We think we should report, three years later, further unexpected developments.

Six years after onset the previously reported clinical and electromyographical signs of polyradiculoneuropathy disappeared; clinical signs progressively mimicked those of amyotrophic lateral sclerosis: the patient developed severe and symmetrical weakness and amyotrophy in the proximal part of the legs, resulting in a severe rolling gait. Weakness and amyotrophy of both arms became severe and were associated with mild pseudobulbar palsy and very explosive stretch reflexes with bilateral Babinski's sign. The patient had no bladder dysfunction and no sensory disturbances. Signs of lesions of the anterior horns started to appear on electromyograms. Computed tomography and magnetic resonance imaging of the brain and cervical myelography showed no abnormality. The rate of progression was very slow.

These new developments greatly modify the signs of what we erroneously called "polyneuropathy." However, the association with the amitriptyline overdose still seems to be probable because of the time course of the events and the very slow rate of progression, which makes amyotrophic lateral sclerosis unlikely. The myelinic degeneration probably induced by amitriptyline might have affected simultaneously spinal roots and spinal cord, and signs of spinal cord disease might have been hidden by such severe initial peripheral signs. We should probably have paid more attention to the very early reappearance of stretch reflexes.

1 Leys D. Pasquier F, Lamblin MD, et al. Acute polyradiculoneuropathy after amitriptyline overdose. Br Med f 1987;294 608 . 